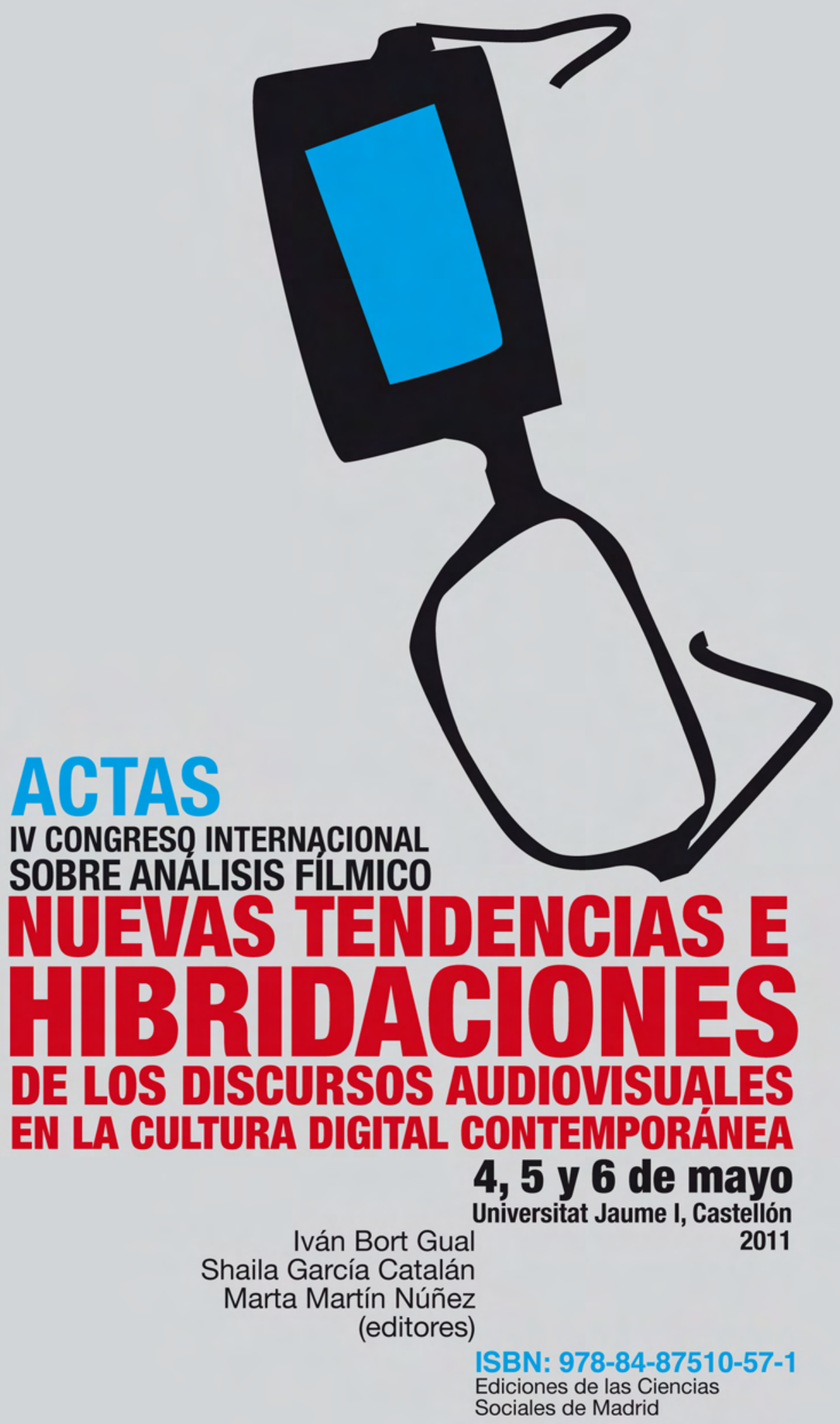




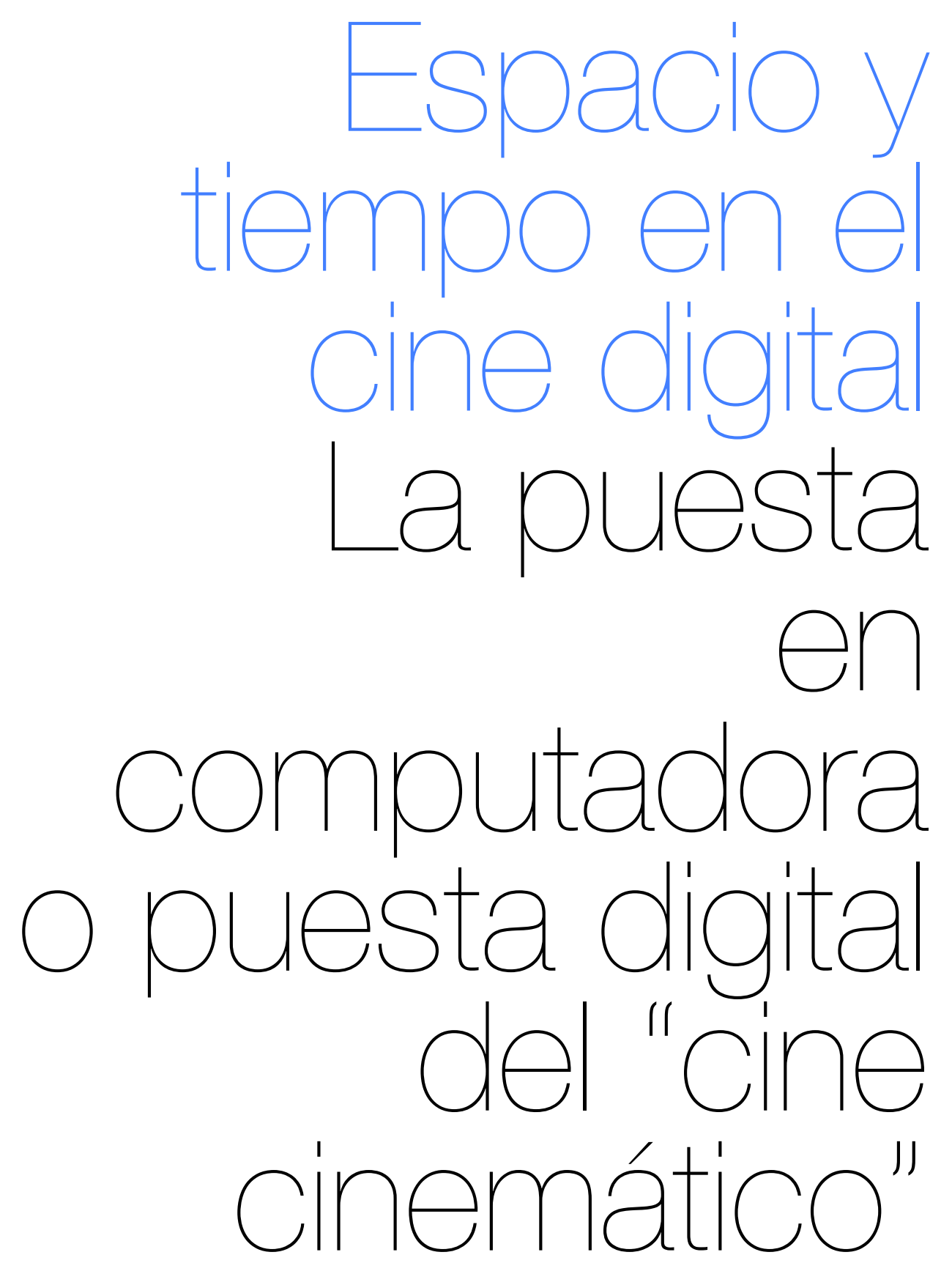

VICENTE CASTELLANOS CERDA

UNIVERSIDAD AUTÓNOMA METROPOLITANA, MÉXICO 


\section{Nociones centrales}

Identifico tres regímenes en la historia [tecnológica] del cine. El que nace con el cinematógrafo y que se apega a la idea original de los hermanos Lumière, esto es, el cine que reproduce el entorno físico y social, la cámara testigo del devenir de la humanidad, el cual derivaría en el cine documental y en los registros etnográficos. El segundo lo potencia y lo convierte en industria económica y cultural en todo el mundo, me refiero al cine que representa el entorno físico y social y para ello recurre a contar historias, a crear estereotipos de personajes, ciudades y situaciones, o por el contrario, a desafiar los atavismos culturales, se trata del cine narrativo o diegético. El tercero es resultado del avance tecnológico, de la convergencia entre lo audiovisual y los procesos de informatización que produjo el ingreso de la computadora en los ámbitos domésticos y profesionales, se trata de un cine que genera imágenes imposibles, fuera de la lógica de la realidad física, que produce una renovación en los filtros a través de los cuales miramos el entorno, se la ha llamado de muchos modos, por ahora diremos que es el cine de la imagen digital o el cine "cinemático".

El problema de nombrar, es un problema de adscripción teórica y tal vez los postulados de la teoría del cine tradicional no sean suficientes para la comprensión de este nuevo estadio tecnológico-cultural del cine. Las categorías de análisis no suelen ir a la par de los nuevos fenómenos, pues siempre hay vestigios conceptuales, ideas por aclarar, nociones que ganan o pierden sentido ante los nuevos fenómenos. Las explicaciones de las imágenes que me ocupan, se hallan en el entrecruzamiento de la semiótica, los estudios del software (Manovich, 2008) y la cultura digital. Las podemos nombrar con los siguientes genéricos, conociendo de antemano sus implicaciones conceptuales:

- cinematografía virtual, si nos atenemos al soporte que las crea y las proyecta, es decir, un cine de pantallas sin necesidad de pasar por un espacio físico para su filmación

- cine digital, en el caso de retomar la tradicional oposición analógico-digital de donde una imagen deja de ser "huella de luz" para aparecer como resultado de un proceso de manipulación en el que «el ordenador se usa frecuentemente para efectuar modificaciones sobre imágenes en cuya producción no ha participado" (Darley, 2002: 40)

- cine sintético (Manovich, 2005), porque se origina a partir de la conjunción de diversas tecnologías de la imagen y por la ausencia de "la naturaleza" para su creación;

- cinegratografía (Manovich, 2005), pues la creación de estas imágenes depende de las técnicas del grafismo, de la animación y del registro cinematográfico, se trata de una nueva escritura, no sólo del movimiento y de la luz, sino también del diseño gráfico aplicado tanto al interior del encuadre como de una secuencia a otra; - cine 3.0 (Dally, 2010), si seguimos la lectura de Deleuze en clave histórica: el cine de la imagen - movimiento (1.0), excesivamente obvio (Bordwell, Staiger y Thompson, $1997^{1}$ ) y narrativo, seguido del cine de la imagen-tiempo (2.0), de

\footnotetext{
${ }^{1}$ Es un cine cuya estructura se basa en pistas y reiteraciones en el plano del relato y de la imagen que de modo permanente anuncian el final.
} 
devaneos espacio-temporales, de rompimiento y de vanguardia ${ }^{2}$, para llegar al cine que promete interactividad con el espectador (3.0);

- hipercine (Lipovetsky y Serroy, 2009), al caracterizarlo por una triple composición hipermoderna reflejada en imágenes hiperborizadas (imagen-exceso), formalmente complejas en su composición narrativa y en su estética visual (imagen-multiplejidad) y en la permanente exhibición de sus procesos de enunciación y autorreferencialidad (imagen-distancia);

- cine cinemático, me atengo a la idea que aquí desarrollo: el cine de los cronosignos; también con fundamento en Deleuze, de los signos del tiempo y del espacio caracterizados por su independencia del entorno físico y narrativo de la película, signos cuya existencia no está forzosamente justificada, y que aparecen con tal fuerza expresiva que renuevan la forma cinematográfica ${ }^{3}$.

Delimito más el tema. Siguiendo a Deleuze (1983 y 1986) parto de la siguiente idea para desarrollar la especificidad de la imagen digital en el cine cinemático: los cronosignos de la imagen digital irrumpen en la organicidad del cine de la gran forma (situación-acción-situación) pero sin convertirse en imagen-tiempo (visión autónoma del contenido). Son cronosignos que sólo en ciertos espacios y tiempos cinematográficos se distancian del relato y del efecto hipnótico, característicos de la imagen movimiento, para rozar la imagen deambulante del segundo régimen histórico del cine, pero con la única función de mostrar el potencial de construcción de un cine sin referentes físicos, menos dependiente del exterior y más cercano a los procesos de fantasía, pensamiento e imaginación de la mente humana.

La imagen digital se caracteriza por la transformación continua del espacio y del tiempo de objetos, personas y entornos evidenciado en transmutaciones muy diversas al interior del encuadre. Seguramente uno de los postulados que más se han visto cuestionados con la aparición y desarrollo de este tipo de imágenes es el que hiciera Christian Metz (1972) respecto a la gran sintagmática del cine. Sabemos que el filmolingüista, fundador de la semiótica cinematográfica, se separa de otros pensadores de la época para proponer el estudio del cine a partir de «segmentos con un cierto grado de magnitud» (Metz, 1972: 188), es decir, el sintagma o agrupación accidental, intencionada, cronológica, simultánea o secuencial de imágenes seguidas de otras, representa el fundamento ontológico del cine. Sin embargo, en la imagen digital la unidad mínima de significación no es más el sintagma, sino el encuadre. El espacio se temporaliza no sólo por la duración de la secuencia medible en segundos, minutos $u$ horas, también por una serie de objetos que se mueven, se transforman y se desplazan simultáneamente en diferentes velocidades y direcciones. Una realidad sin ataduras a las leyes clásicas de la física es posible con la imagen digital.

En las imágenes no digitales el tiempo era el elemento principal del montaje cuadro por cuadro, pero ahora lo es también del encuadre, es como si el tiempo en el cine se hubiera encuadrado. La imagen cinematográfica tradicional tiene una ontología

\footnotetext{
${ }^{2}$ La segunda en la historia de este medio que se iniciara en Europa después de la Segunda Guerra Mundial.

${ }^{3}$ Respecto al sonido, es posible referirnos igualmente a un "sonido sonográfico" cuyos referentes con la realidad se crean al momento de generar el sonido mismo, por ejemplo: ¿cómo se escucha en el cine la antigravedad, la destrucción del mundo, el desplazamiento de un carro sin contacto con el piso?
} 
propia que en palabras de André Bazin (2001) momifica ${ }^{4}$, condición que cambian en la imagen digital, pues si bien toda forma física filmada digitalmente mantiene esta característica inevitable de permanencia y de apego a la realidad de origen, no acaban ahí las posibilidades de su tratamiento cinematográfico final. Al tiempo y al movimiento de objetos momificados se suma el tiempo y los movimientos cinemáticos, esto es, aquéllos generados por el registro y la posproducción digital.

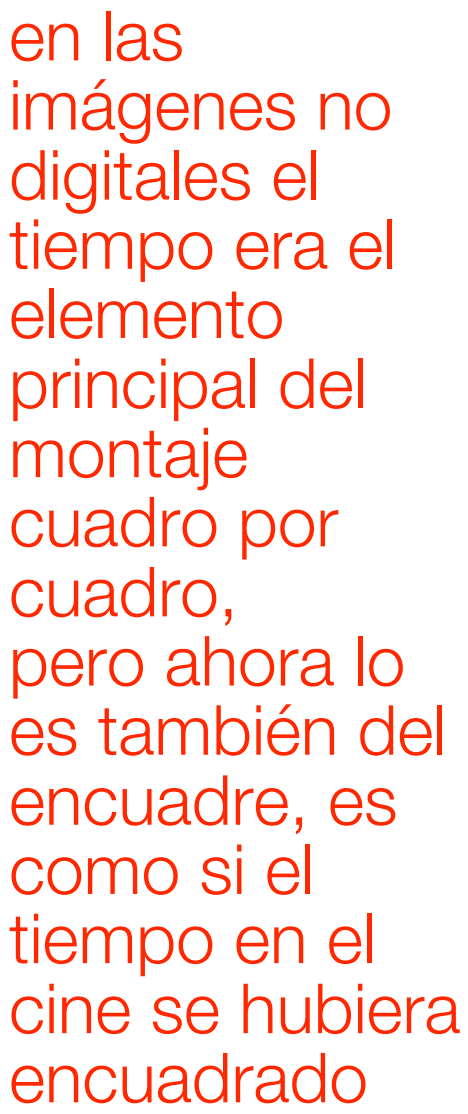

Se pueden distinguir, entonces, dos tipos de tiempos y movimientos al interior del encuadre: el de los objetos precinematográficos y el cinemático. Mientras que los primeros pueden tener una manifestación de su existencia externa al cine y siguen un flujo lógico y apegado a la realidad física, los segundos son propios del cine y transforma el entorno, los personajes y la cámara misma en simultaneidad.

Presenciamos una nueva estética audiovisual, resultado de la manipulación multimodal del espacio y del tiempo por cuatro tecnologías que convergen para ello: la computadora, el cinematógrafo, la fotografía y la animación. Incluso el rol del cineasta cuyo labor se concentraba en gran medida en el rodaje, se ha extendido a la puesta en computadora tal y como trabaja un diseñador gráfico el espacio y el tiempo en la superficie de un soporte plano. Se trata de llevar la estética del collage a la imagen cinematográfica mediante la selección y tratamiento diferenciado de capas de imágenes diversas que se yuxtaponen de modo lógico o no. Los resultados son diversos, uno de éstos consiste en visualizar nuevas formas de transición, como cambiar el fondo sin que sufran alteración alguna los objetos que aparecen en el encuadre, o la posibilidad de dividir la pantalla en múltiples fragmentos. En cuanto a la posproducción de la imagen digital, se cuenta con infinidad de comandos de carácter tecno-nostálgicos en los menús de los programas (grano reventado, virados al sepia o acelerado a 16 cuadros por segundo) que pueden mezclarse con otros innovadores (selección de fotogramas claves, filtraje selectivo o movimientos independientes de los objetos). La consecuencia de esta transformación es que los cronosignos de la imagen digital organizan de un nuevo modo las relaciones espacio-temporales con la narrativa. Ahí están los ejemplos de lo que podríamos llamar el cine-mente de Christopher Nolan en Origen (Inception, 2010). Lo llamo cine-mente pues para el psicólogo Hugo Münsterberg (1970) es en la mente del espectador donde la película se vive e

\footnotetext{
4 «La imagen (fotográfica del cine) puede ser borrosa, estar deformada, descolorida, no tener valor documental; sin embargo, procede siempre por su génesis de la ontología del modelo. De ahí el encanto de las fotografías de los álbumes familiares (...), la fotografía no crea - como el arte - la eternidad, sino que embalsama el tiempo; se limita a sustraerlo de su propia corrupción» (Bazin, 2001: 28 y 29).
} 
interpreta a partir de procedimientos de simulación y estimulación. En la medida en que la máquina cinematográfica simula las formas de la mente, el espectador ve estimulada su experiencia cinematográfica. Al respecto, el teórico estadounidense, Dudley Andrew, sintetiza este pensamiento:

La maquinaria compleja (cámaras, proyectores y todo el mecanismo del proceso), al producir imágenes fijas intermitentes, ha sido desarrollada para trabajar directamente sobre la materia prima de la mente. El resultado es el cine (Andrew, 1978: 29)

Ahora bien, ¿qué tanto esta nueva estética ha alterado los valores del photoplay ${ }^{5}$ que describiera muy tempranamente Münsterberg? Podríamos afirmar que la imagen digital remite a nuevas formas de la memoria, la atención, la fantasía, en suma, a una mirada de segundo orden o de otro régimen escópico, concentrado en mutar el principio de realismo dado por el registro mecánico y óptico de la imagen tradicional por otro más cercano a la composición de imágenes, construidas con pocos o sin ningún elemento proveniente de la realidad física. En esto sentido, la imagen digital desafía la memoria al no limitar su función al recuerdo, sino al ampliarla a la reconstrucción de pasados diversos; por su parte, la atención se multiplica como ocurre en los casos del plano secuencia, la edición de capas múltiples o la división de la pantalla; finalmente, la fantasía consiste en igualar imaginación y pensamiento con la visualización de éstos en pantalla.

En suma, el tiempo-espacio y el movimiento en el encuadre temporalizado se caracteriza por:

- el desplazamiento de la unidad espacio-temporal de la secuencia, hacia un conjunto de capas yuxtapuestas en un mismo encuadre;

- en consecuencia, se facilita la combinación de elementos espacio-temporales dentro de una escena, formas que cambian constantemente, algunas imposibles en la imagen tradicional;

- los objetos y la cámara mostrados en pantalla propician una sensación inmersiva, de ahí que no sea gratuito el renacer del cine en tercera dimensión, es decir, el 3D como plataforma básica del diseño espacio-temporal de la imagen digital.

¿Este cine es un cine remediado (Bolter y Grusin, 2000) o como propone Manovich (2008), es un cine hibridizado? La noción de remediación implica dos características, por una parte que un nuevo medio conserva elementos de otros que le antecedieron y esto deriva en una especie de re-ensamblaje de aquello que se conserva junto con los elementos recién incorporados. El cine digital, bajo esta idea, sería una especie de medio mejorado, como en su momento representó la incorporación del sonido y de la película en color. Sin embargo, al ser la computadora un metamedio al "contener una amplia gama de medios ya existentes, a la par de los no inventados todavía» (Manovich, 2008: 26), y al llevar a un estadio superior, como he insistido, la condición ontológica del cine de mostrar aquello que se conoce o no mediante la particularísima forma de la expresión cinematográfica, el cine digital es más que una remediación tecnológica. Se trata, otra insistencia, de un cambio en el régimen escópico que conduce a una mirada

\footnotetext{
5 «El photoplay nos habla de la historia humana, superando las formas del mundo exterior, llamadas: espacio, tiempo y causalidad, y ajustándolas a los eventos de las formas del mundo interior, llamadas: atención, memoria, imaginación y emoción» (Münsterberg: 1970, 173).
} 
cultural que nunca antes se había dado. Coincido con Andrew Darley que estamos en el umbral de una cultura visual digital cuya estética «posee conexiones directas con la producción de ilusión, con la magia y con el efecto especial, con formas de imagen extravagantes, extravertidas y retóricas» (Darley, 2002: 298).

Por otro lado, la computadora no suma "algo" más al cine, la computadora hibridiza al cine con los lenguajes de la informática, de la animación, de la imagen fija fotográfica y del diseño gráfico. Se trata de una transformación profunda, no de una mejora. El cine se tardó más de cien años en conseguir el anhelo de su propia condición artística: mostrar con realismo lo imposible, y lo logró sólo cuando la computadora se sumó a su proceso de creación.

El cine digital, en estos momentos de su desarrollo histórico como lo estuvo el cine óptico-químico a principios del siglo XX con la aparición de las primeras vanguardias, está preocupado por él mismo, por su condición de medio y arte. Los reclamos de la cámara como aquel elemento que adquiere protagonismo con independencia de los actores a través de los juegos hiperbólicos de acelerados y "ralentizados" de objetos en el encuadre, las tomas desafiantes de la realidad física y la representación audiovisual de mundos extraordinarios o catástrofes apocalípticas, son sólo algunos ejemplos de la autorreflexibilidad de la imagen digital contemporánea.

Afirmo que este cine construye representaciones novedosas del tiempo y del espacio. Para explicar este postulado, es necesario retomar, de la noción de medio híbrido de Manovich, la característica referente al intercambio de propiedades que se da cuando dos medios interactúan, dando como resultado nuevas estructuras de representación. Como he señalado, el tiempo no es más el fundamento del montaje ni el espacio del encuadre, de las nuevas estructuras de la hibridación se derivan los encuadres móviles y los montajes extendidos con cambio de lugares $y$ momentos sin que se altere la totalidad de la imagen. Existe una lógica cultural en estas

la computadora no suma "algo" más al cine, lo hibridiza con los lenguajes de la informática, de la animación, de la imagen fija fotográfica y del diseño gráfico. Se trata de una transformación profunda, no de una mejora imágenes cada vez más evidente: la co-presencia de medios, elementos y lenguajes que nos obligan a mirar, por tanto comprender, el entorno en simultaneidad.

Manovich propone llamar a esta lógica "deep remixability" en cuya base se halla la hibridación que «no es sólo el contenido de diferentes medios de comunicación, sino también de sus técnicas fundamentales, de los métodos de trabajo y de las formas de representación y expresión» (Manovich; 2008: 130). Se podría decir que asistimos a la cultura visual remezclada cuya potencia aún está por verse y experimentarse debido al entrecruzamiento del cine y la computadora.

\footnotetext{
${ }^{6}$ Dada la dificultad de traducción, he decidido usar la noción en el inglés original.
} 


\section{La puesta en computadora o la puesta digital}

La organización del espacio-tiempo en el cine se ha estudiado a partir de tres divisiones más o menos diferenciadas: la puesta en escena, la puesta en cuadro o cámara y la puesta en serie. Escena-cámara-montaje en conjunción, dan como resultado una imagen en movimiento. Se filma algo con un aparato diseñado para eso, que arroja fragmentos visuales y sonoros para que un segundo momento sean yuxtapuestos. Analistas del cine han profundizado en algunos de sus aspectos, ahí está la bibliografía considerable acerca del montaje como elemento distintivo del arte cinematográfico, o bien, los textos referidos al encuadre, al fotograma o a la construcción narrativa de la escena. Tres macrocategorías útiles para el estudio del cine pre-digital.

Una cuarta macrocategoría es necesaria ahora. La he nombrado puesta en escena en computadora o puesta digital. Consiste en un proceso de imaginación, previsualización y realización de todo aquello real o fantasioso que es posible generar en la computadora, y que puede o no estar justificado en la realidad física, en la narrativa o en la estructura de género de una película. Si partimos del hecho de que toda persona y objeto puede ser tratado digitalmente, la puesta digital se caracteriza por la ausencia de límites, no obstante sí los hallamos en cuanto a tratamiento se refiere. Afirmo, por ahora, que es en esta puesta donde se trabajan las coordenadas espacio-tiempo de la imagen contemporánea, una imagen cinemática que acentúa la condición móvil de la imagen en su relación con lo estático. Los valores cuantificables son el dinamismo versus la estaticidad.

"Cine cinemático" es una noción etimológicamente reiterada, pero que describe el nuevo carácter histórico y ontológico del cine: un cine cuya especificidad espaciotemporal es superior a la de su antecesor-sostenido en la única tecnología del cinematógrafo, al presentar una gran número de posibilidades del juego entre lo móvil y lo inmóvil en un solo encuadre-sostenido por las tecnologías del cinematógrafo, la fotografía, la animación y la computadora. Se trata de un cine contra el montaje lineal, de aquél que se hace a partir de la yuxtaposición de secuencias con cierto grado de coherencia lógica o cronológica. Ahora bien, no todo cine digital es cine cinemático, es en realidad una posibilidad de manipulación artística a disposición de sus creadores.

Propongo distinguir entre el tiempo y espacio de la imagen en su conjunto, así como de los personajes y de los objetos en particular, en función de una triple posibilidad: lo propiamente cinemático (por ejemplo, el movimiento de una cámara que irrumpe sin justificación el relato o exhibe el trayecto de un objeto con la finalidad de recorrer el trayecto en sí mismo y no por alguna intención narrativa), el grado de tratamiento digital de los objetos y de las personas al interior de un encuadre que puede ser hipercinemático (la visualización en cámara lenta del movimiento de una bala) o hipocinemáticos (el retoque digital con fines de corrección). La tercera posibilidad, la entiendo como la mezcla o hibridación de todo lo visible en el encuadre que tiene características medibles de duración, frecuencia, trayectoria y velocidad. Un movimiento muy lento puede ser mostrado muy rápido y en tan sólo una fracción de segundos, o por el contrario, el movimiento más veloz que uno pueda imaginar, puede ser visto en pantalla en capas de imágenes fijas congeladas y repetidas en un mismo encuadre. siguiente esquema muestra gráficamente esta propuesta. 


\section{Visibles}

Tratamiento

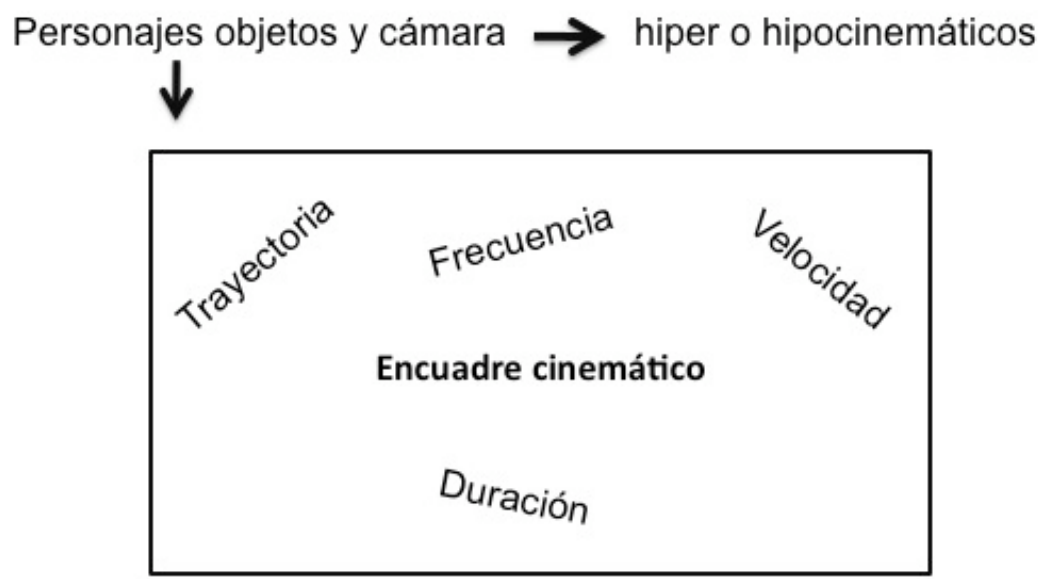

Identifico, junto con Dally (2010), otro tratamiento de la imagen digital: la multipantalla. Como herencia del cómic, el cine tradicional ya proyectaba pequeños encuadres simultáneos, sea de una misma o de diferente secuencia. La variante de la multipantalla digital respecto a su antecesora sólo se distingue en el cine de tercera dimensión, al presentar el collage de secuencias de tal modo que unos fragmentos parecen estar más cerca del espectador que otros, es decir, unos se ubican en la profundidad de la pantalla y otras en primer plano. Experiencia visual que no es posible en el cine de segunda dimensión aunque se trate de una película realizada en su totalidad con tecnología digital.

El cineasta-diseñador, o el equipo de producción de una película, trabaja con intenciones no sólo narrativas, sino también con intenciones cinematográficas que atañen exclusivamente a las posibilidades de expresión de la forma artística del cine. Manovich (2005), considera que el cine digital de Hollywood busca por todos los medios "esconder el truco", para favorecer el relato. Se trata de generar la más artificial, sintética e imposible imagen digital pero con el realismo de un daguerrotipo. Esta intención de ocultar lo que Benveniste (1971) llamó el aparato formal de la enunciación, convive actualmente con su opuesta en el encuadre en simultaneidad, cuyo antecedente puede ubicarse en el movimiento dadaísta del principios del siglo pasado, al develar la carga ideológica del artista o producir el efecto de extrañamiento en quien mira al poner juntas capas de imágenes contradictorias o imposibles. Ambas herencias se pueden rastrear en la puesta digital al no ceñirse a los límites del mundo físico del rodaje. En nuestros días no es suficiente un cine del registro in situ que va del plató a la mesa del montaje, más bien, se procura un cine que se monta, se recorta y pega, en la computadora.

En resumen, del story board como documento de previsualización, de la locación como registro audiovisual, del montaje como proceso de construcción secuencial de un film, hemos pasado a la composición digital del encuadre en un cine en el cual el espacio se temporaliza y el tiempo se espacializa. Esta composición en capas, permite el control selectivo de los personajes, objetos, ambientes y cámaras, por lo que las posibilidades de hibridación y manipulación crecen 
exponencialmente: «En la composición digital cada elemento visual puede ser modulado independientemente de varios modos: cambiando su tamaño, recoloreándolo, animándolo, etc» (Manovich, 2008: 144).

3. Inventario y categorización de la puesta en computadora o puesta digital Coincido con Deleuze (1985) que el tratamiento del tiempo en el cine es múltiple. Es presente en la experiencia del espectador (el tiempo que transcurre), es presente, pasado o futuro en la narración (el tiempo de la diégesis), pero también, en sus situaciones, ambientes, personajes y objetos, el tiempo se acumula, se expande, retrocede (el tiempo cinemático). No sólo me refiero a las posibilidades de la tecnología del cinematógrafo: la cámara lenta o rápida, las acciones simultáneas en el tiempo pero en espacio distintos del montaje alternado, el plano secuencia o la división de la pantalla, también incorporó las propias de la hibridación tecnológica de la que deriva una imagen en capas de tiempos y espacios diferenciados en simultaneidad. La imagen digital es un tipo de cine condensado, lo que antes era propio de toda la secuencia, ahora lo es del fotograma, ese maravilloso artificio (Barthes, 1986) inmóvil-móvil suma de todos los esfuerzos del arte de la manipulación espacio-temporal, en el fotograma digital no se representan estas coordenadas cinematográficas, se diseñan los cronosignos de la imagen digital.

Distingo entre el espacio-tiempo del acontecimiento cuya principal función es la constatación de que algo ocurre bajo cierta lógica justificada en la realidad o en el género cinematográfico, del espacio-tiempo del encuadre digital cuyos principios son, en palabras de Manovich (2005), la variabilidad y la modularidad. Cada capa se diseña de modo autónomo, aunque unida con otras formen un todo, esta posibilidad de trabajar con módulos de imágenes, algo así como con unidades mínimas de significación más pequeñas y fragmentadas que la secuencia cinematográfica, permite presentarlas y montarlas con variaciones considerables en cuando duración, velocidad, trayectoria y función narrativa.

La profundidad de campo y la trayectoria de la cámara habían sido los valores claves en la comprensión del espacio cinematográfico, pero la imagen digital suma a estos dos valores, la variación propia de los movimientos virtuales de la cámara en un juego de velocidades, trayectos y direcciones muy diversas. Por su parte, el montaje había sido el valor cinematográfico de tipo temporal por excelencia, pero también se modifica en la imagen digital al no ceñirse a la secuencia. La idea del plano secuencia, es decir, de un cambio de planos sin cortes, es perfeccionada en el cine digital al ampliar las variaciones, por ejemplo, la multipantalla con profundidad de campo característica de las películas 3D, que ya he mencionado.

Rocco Mangieri ${ }^{7}$ identifica los siguientes elementos de lo que él llama el tiempo fílmico en el discurso cinematográfico: la elipsis, el resumen, la dilatación, la extensión, la repetición, la pausa o detención, la anticipación, elementos acentuados en presencia y uso en la imagen digital por el tratamiento que reciban en cuando duración, frecuencia, velocidad y trayectoria.

Siguiendo esta lógica de inventariar, el espacio fílmico se compone por: los bordes del encuadre y "la pared invisible" a partir de la cual la cámara ve; la profundidad de

\footnotetext{
7 Seminario Espacio, tiempo y personaje en la escritura filmica y cinematográfica, Universidad Autónoma del Estado de Morelos, México, enero 2011.
} 
campo tanto en segundo como en tercera dimensión; la fragmentación del espacio que deriva en la muy conocida clasificación de los planos cinematográficos a partir de la cantidad de información visual que se muestra tomando como parámetro el cuerpo completo del ser humano; la dirección del movimiento y de las miradas, así como el espacio agregado al espacio dado por ese otro maravilloso artificio llamado fuera campo.

Con estos elementos más o menos ordenados podemos describir las articulaciones posibles entre el espacio y el tiempo en el cine digital. Propongo comprenderlos con dos lógicas de partida: la dinámica espacial y los vectores temporales.

\section{Vectores temporales}

\begin{tabular}{l|l}
$\begin{array}{l}\text { Elementos: } \\
\text { elipsis, resumen, dilatación, } \\
\text { extensión, repetición, } \\
\text { pausa, anticipación. }\end{array}$ & $\begin{array}{l}\text { Tratamiento: } \\
\text { duración, frecuencia, } \\
\text { velocidad y trayectoria. }\end{array}$ \\
\hline $\begin{array}{l}\text { Elementos: } \\
\text { los bordes del encuadre y } \\
\text { “la pared invisible", la } \\
\text { profundidad de campo, los } \\
\text { planos, la dirección del } \\
\text { movimiento y de las } \\
\text { miradas y el fuera campo. }\end{array}$ & $\begin{array}{l}\text { Tratamiento: } \\
\text { diseño por capas, segunda o o dimensión, una } \\
\text { tercerantalla o multipantalla. }\end{array}$ \\
\hline
\end{tabular}

\section{Dinámica espacial}

Las articulaciones se condensan en dos imágenes base del cine digital: el momento congelado - con sus variantes - y la acción en vivo. El oxímoron de la primera es provocador conceptualmente pues el movimiento es transcurso y duración, el cine mismo lo es, pero lo cierto es que una de las imágenes más comunes con la digitalización ha sido aquella que muestra en un mismo encuadre movimientos, congelados, acelerados y/o pausas. Por su parte, la acción en vivo es como mirar al mundo con nuestros ojos directamente, - mientras el cine fragmenta y luego lo recompone cinematográficamente mediante un apego estricto a la continuidad espacio-temporaŁ, nuestra experiencia nos dicta que todo cambia de modo continuo, sin cortes o disolvencias que medien, y con la acción en vivo esto es posible experimentar en la pantalla de cine.

Muchas otras articulaciones se pueden derivar de hibridizar estos elementos y tratamientos gracias a las tecnologías. Por ejemplo, referente al momento congelado, en la película The Green Hornet (Michel Gondry, 2011), uno de los personajes principales, Kato, justifica narrativamente la puesta en computadora de 
la imagen digital, pues tras una exhibición en pantalla de tiempos simultáneos acelerados y condensados, de trayectorias caóticas de la lucha cuerpo a cuerpo y de objetos que se multiplican en sí mismos, así como de un fuera campo que se actualiza selectivamente al aparecer el personaje caprichosamente en cualquier lugar, éste explica que cuando se halla en peligro, su corazón cambia de ritmo y su cerebro piensa muy rápido (situación que se le presenta al espectador en cámara lenta) y actúa a una gran velocidad, igualmente, muy lenta y condensada para el espectador. Estas imágenes que inauguraron en 1999 los hermanos Wachowski con su Matrix (The Matrix) siguen teniendo el mismo principio, pero con mayor gama de variaciones según el avance de las tecnologías de la posproducción en el cine. Otra secuencia digital representativa de los alcances que ha tenido por más de una década la acción en vivo, la ubico en el fabuloso plano secuencia del argentino Juan José Campanella, El secreto de sus ojos (2009), en una desafiante construcción secuencial con sus complicados nodos de transición para evitar la notoriedad en los cortes. Se trata de una imagen que inicia con una toma aérea de un estadio de fútbol, se detiene con los personajes principales mezclados en la multitud de las gradas, continua un juego más o menos clásico de perseguidorperseguido, para concluir en plena cancha con la caída del perseguido. Una toma de acción en vivo de varios minutos que el artificio de lo digital representa con el realismo del «yo lo vi».

Considero que puedo condensar la conclusión principal de este trabajo del siguiente modo: entre el cine de la gran forma, el sensorio-motor como también lo llamó Deleuze, que respeta un régimen orgánico cuyo espacio y tiempo están inmersos en la lógica transparente del relato y el cine de la imagen-tiempo, el de la visión autónoma de la cámara, de los contenidos y de personajes que deambulan en lugar de actuar para alcanzar algún fin, el cine digital irrumpe entre ambos, pero sin llegar a asimilarse a ninguno de los dos regímenes, constituyéndose en un tercero en el cual el espacio y el tiempo se generan, tratan y exhiben no más por las intenciones del relato o del cineasta, sino por el juego móvil-inmóvil al interior del encuadre de objetos y personas y por la sucesión de planos en el montaje que conservan un elemento sin transformación. Son cronosignos evolucionados gracias a la convergencia cine-computadora.

\section{BIBLIOGRAFÍA}

ANDREW, Dudley (1978): Las principales teorías cinematográficas. Gustavo Gili, segunda edición. Barcelona.

BARTHES, Roland (1986): Lo obvio y lo obtuso: imágenes, gestos, voces. Barcelona. Paidós.

BAZIN, André (2001): ¿Qué es el cine? Rialp, quinta edición. España.

BOLTER, Jay David y Richard Grusin (2000): Remediation: Understanding New Media. MIT Press. USA.

BORDWELL, David, STAIGER, Janet y THOMPSON, Kristin (1997): El cine clásico de Hollywood: estilo cinematográfico y modo de producción hasta 1960. Paidós. Barcelona.

DALY, Kristen (2010): "Cinema 3.0: The Interactive-Image", Cinema Journal, 50, Number 1, Fall, pp. 81-98. 
DARLEY, Andrew (2002): Cultura visual digital: espectáculo y nuevo géneros en los medios de comunicación. Paidós. Barcelona.

DELEUZE, Gilles (1983): La imagen-movimiento. Estudios sobre el cine 1. Paidós. Barcelona.

DELEUZE, Gilles (1986): La imagen-tiempo. Estudios sobre el cine 2. Paidós, primera reimpresión. Barcelona.

LIPOVETSKY, Gilles y SERROY, Jean (2009): La pantalla global: cultura mediática y cine en la era hipermoderna. Anagrama. Barcelona

MANOVICH, Lev (2005): El lenguaje de los nuevos medios de comunicación. Paidós. Barcelona.

MANOVICH, Lev (2008): Software takes command. Creativie Commons License.

METZ, Christian (1972): Ensayos sobre la significación en el cine. Editorial Tiempo Contemporáneo. Buenos Aires.

MÜNSTERBERG, Hugo (1970): The Photoplay. Arno Press \& New York Times. USA. 